\title{
A hermeneutic framework for responsible technical interventions in low-income households - mobile phones for improved managed health care as test case
}

\author{
MMURRAY' AND E WOLFF"
}

\begin{abstract}
In this article the authors, a philosopher and a social development practitioner, formulate recommendations for responsible planning of technical interventions in health care relations under circumstances of uncertainty and moral risk. It is proposed that the hermeneutic approach followed in this article could serve as a heuristic guide to research and development teams in the planning phase of similar projects to proceed in a responsible manner. The introduction of mobile phone technology by a managed health care service provider to clients from a low-income South African context is used as a test case to illustrate the value of the proposed heuristic approach. The strength of this approach is situated in its coordination of general anthropological considerations, with interpretative attention to particularities. The test case is a relevant to the problem since it cannot be assumed that the same habitus of acquaintance with the mobile phone apparatus has been formed in the low-income South African context as in contexts or societies where people have been using telephones for decades.
\end{abstract}

Key words: Managed health care; responsibility; technical intervention; mobile phones; communication in rural health care; heuristics; hermeneutics

Disciplines: Development Studies, Philosophy, Medicine, ICT Studies, Organization Studies.

\section{Introduction}

In the South African context, where the current study is situated, the term managed health care is commonly used to refer to the range of techniques intended to reduce the cost of providing health benefits while simultaneously improving the quality of care rendered (adapted from NCBI). According to Chabikuli et al (2008) three key role players are involved in the production of managed health care services: the patient and his/her family (first party), the health care provider (second party, e.g. a doctor) and the medical insurance and/or medical aid administrator (third party). Ideally, managed care seeks to define the roles and duties of each party in such a way that health care cost escalation is contained and benefits of the services to the patient optimised.

In June 2005 a managed health care organisation (MHCO), Enablemed, approached the NOVA Institute to form an alliance to jointly embark on a programme to improve health care to their clients, in particular to extend their offering of services to people of an income

1. Montagu Murray is a programme manager at the NOVA Institute (http://www.nova.org.za). Email: montagumurray@nova.org.za.

2. Ernst Wolff is professor in the department of philosophy, University of Pretoria. Email: ernst.wolff@up.ac.za. 
bracket that would normally fall below the minimum requirements for managed health care. NOVA studies quality of life in low-income households in Southern Africa, typically the milieu from which most of Enablemed's existing and prospective clients derive. ${ }^{3}$ From the outset the parties agreed that good communication and personal relationships between the three managed health care role players would be essential guiding criteria for the project. When the idea gradually emerged that mobile phone technology as means of communication could possibly be employed to improve the health benefits of clients, these shared values lead to at least two decisions: i) The ethical pitfalls of a one-sided technocratic implementation of mobile technology had to be avoided, and ii) the introduction of mobile technology to facilitate communication between the key role players had to be designed to complement rather than substitute human interaction.

\section{Problem Statement}

The above decisions to guard against a one-sided technocratic attitude and to regard the human being as an agent in the application of technical means have implications for the problem at hand. It means that the research and development team has to orientate itself to the possible ethical and sense making (hermeneutical) implications of its innovation process on the people concerned. The particular nature of the challenges involved in initiating such a project can be highlighted by situating the preparation of the project within the phased approach to R\&D and implementation used at the NOVA Institute.

\section{Nova Phased Approach}

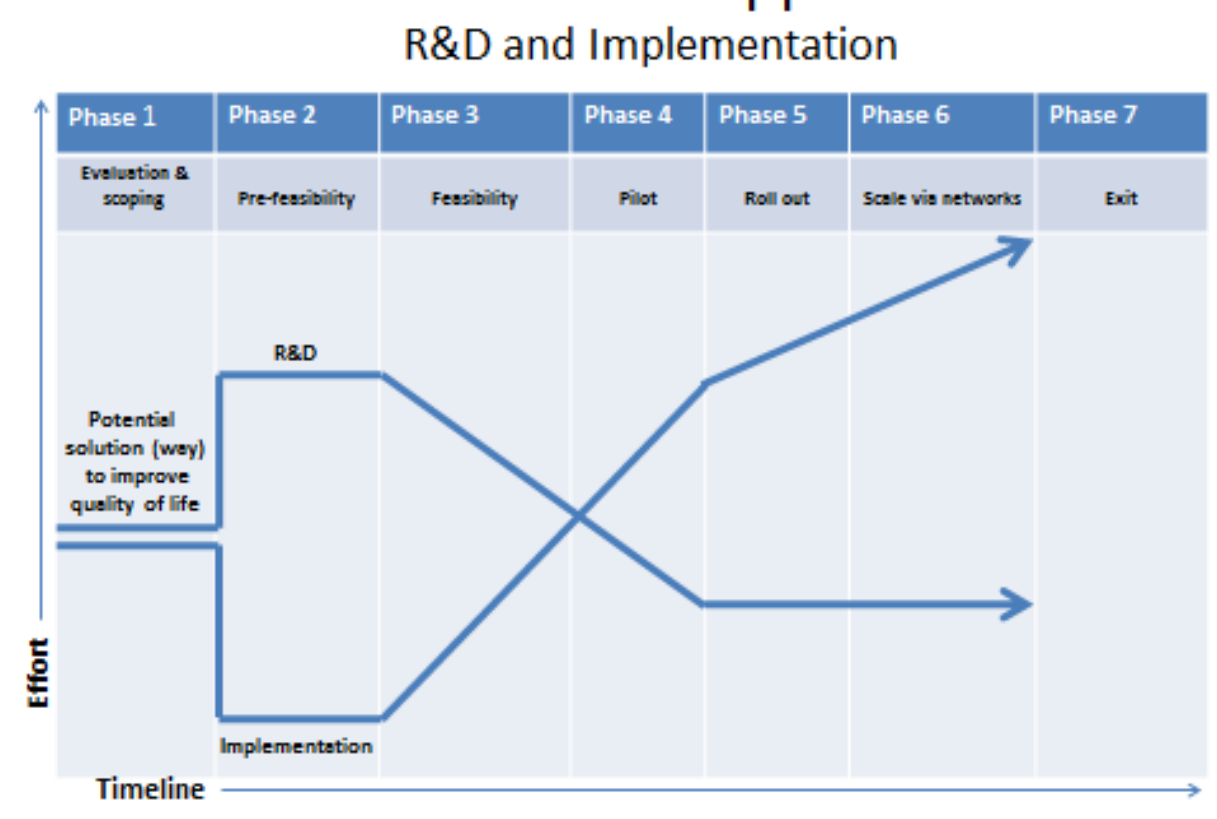

Two elements of this diagram should retain our attention. First, in the initial phases of innovation, R\&D plays an important role in guiding the entire project; second, even when full scale implementation is reached, $\mathrm{R} \& \mathrm{D}$ does not end, since it accompanies the implementation process critically. It is this task of preparation and reflecting accompaniment

Funding for this project was attained through the THRIP Programme in collaboration with the University of Pretoria. 
of the innovation process that is our object of concern in this article. Applied to our case study, the following four factors of this innovation process should at least be taken into consideration - it would entail

i. intervening in the efficient and cost effective rendering of services by the $\mathrm{MHCO}$,

ii. intervening in the household milieu of the clients by activating the new mobile phone technologies within the intimacy of health related issues, thus

iii. linking the household with the medical service and medical financing industry in previously unknown manners, and

iv. that all of these take place in a context where not only the cultural background of the inventors of the technical artefact and the communicational system differ from that of the clients, but also where the clients show enormous cultural difference amongst themselves.

The aim of this article is to critically document and systematise the authors' subsequent research on the means by which to prepare and launch responsible work on such a problem. For the purposes of this reflection we define responsibility as (i) the concern to act (ii) by using the best knowledge available, under circumstances of uncertainty concerning the possible consequences of actions (iii) enforcing it with a heuristics directed at the future, (iv) in order to be able to justify to all relevant parties that the necessary has been done in the early phases of a project to avoid likely negative consequences (derived from Jonas 1979:61-68). We would thus consider an approach to the described task to be responsible, when it could be reasonably argued that its future applications are likely to have a beneficial impact on all the key managed health care role players with their respective (and even contradictory) interests. Since the development of this kind of project is expensive and time consuming, and since it contains a high level of risk of negative impact on the people concerned, the importance of the preparatory phase of the project is considerably increased. Hence the problem to be reflected on in this article: how could a research and development team that prepares such a project that evidently aims at design specification(s) of a new product or service, simultaneously orientate themselves to the possible ethical and hermeneutical risks of their innovations on the people concerned? While answering this question we shall show what advantages there are in combining the skills of a development specialist and a philosopher in this phase of the project

It will not be possible to consider the impact on all role players in this article. Our focus will be on how a research and development team can anticipate certain possible negative consequences of the introduction of new technologies on the living standard of their potential beneficiaries. Our notion is that the hermeneutic framework presented in this article could help to guide a research and development team in the early phases of a project to anticipate some ethical pitfalls and thus to demonstrate greater responsibility when introducing new technologies to lowincome households.

As background to the hermeneutic theory we need to briefly comment on the roles and duties of key role players in managed health care $(\$ 3)$. This is followed by a brief presentation of the results of a study in a rural South African area (typical of where Enablemeds clients stem from) regarding the availability and usage patterns of mobile phones - and an indication of the socio-cultural significance of these findings $(\$ 4)$. We then present the hermeneutic framework we believe could be of help as a heuristic component of a responsible research and development process. We also illustrate how this framework may be applied, by taking mobile telephony as an example $(\S 5)$. In conclusion a few suggestions are made on how the 
interpretative strength of this framework could be made productive for a $R \& D$ project, like the one presented in our case study $(\S 6)$.

\section{Roles and Duties of the Managed Health Care Role Players}

The MHCO has the task to assist in mediating a fair transaction between the patient and health care service providers. Economically speaking this means that the MHCO wants to keep the trust of the patient (buyer) and the medical service provider (seller) by brokering a fair transaction. By doing so, value could be added for both the buyer and the seller. The $\mathrm{MHCO}$ has the best opportunity to mediate a fair transaction when the client has access to the maximum benefits which he/she uses sensibly and the seller makes a good profit discreetly. The MHCO wants to accomplish this by delivering a quality service costeffectively.

Chabikuli et al argued that, of the three key role players in managed care, the health care provider is usually the best informed on medical matters and is therefore at the advantage when deciding on what the appropriate medical treatment should be for a particular episode of illness. This state of affairs could be described as an asymmetry of information (Chabikuli et al 2008, p. 66a). Chabikuli et al further asserted that the asymmetry of information is critical in creating what is known as moral hazards. One such moral hazard is 'over-servicing' that can occur if the health care provider has an incentive to do so. For example, in the fee for service payment method, the more services the health care provider renders the more reimbursement he/she receives. This hazard is complicated by the cost of decisions by the provider e.g. hospitalisation and technological investigations, which generate income to a strong health industry. Another moral hazard is 'under-servicing' in the case of capitation payment whereby the less a provider spends on the patient the more profit is made. The patient can also request more unnecessary service in a capitated arrangement if no limits are set to the benefits. A good managed care organisation will seek to design contracts and benefits in such a way that moral hazards are kept to a minimum. The negative consequences of such moral hazards could be exacerbated under circumstances of low income.

The patient and his or her family can get better benefits at a reduced cost, provided that they keep to the rules of their specific package. These rules could include requirements such as a call for authorisation to the call centre of the MHCO before accessing particular medical services, for example before being hospitalised or seeing a specialist. Since the role of the doctor is crucial in this regard, one important requirement could be to expect of patients to choose one regular health care provider in their area of residence.

Previous research undertaken by NOVA can be used to illustrate the dynamics involved in the relations between different role players in managed health care. In 2005 the managed health care organisation Enablemed approached the Functional Household Programme of the Nova Institute and the University of Pretoria to assist with research to determine if their clients are satisfied with their medical aid packages and to get an idea if the clients are informed about their benefits and how to access them. Murray (2005) undertook a contentment investigation amongst health plan members under the administration of Enablemed at three different sites in South Africa: Alrode in Gauteng, Piet Retief in Mpumalanga and Somerset West in the Western Cape. One of the main findings was that the managed care principle of going to one registered doctor is a source of discontentment amongst members in Alrode and Piet Retief - but not as much in Somerset West in the 
Western Cape. Murray suggested that further research is necessary to understand this state of affairs and to determine if language and cultural factors played a part, since in both Alrode and Piet-Retief - where the discontent was strongest - all the interviewees where Zulu and Sotho speaking Africans, whereas the majority of the members in Somerset were Afrikaans speaking "Coloureds" (Murray 2005:3-8). Murray further found that misconceptions, misunderstandings, confusion and suspicion with regard to the aims and functioning of managed care still prevail amongst a substantial number of Enablemed's clients.

In 2006 a qualitative enquiry was done to gain deeper insight into the doctor hopping phenomenon observed amid the Enablemed clients in the form of key informant interviews and focus group discussions. Generally, the participants expressed a greater willingness than in 2005 to adhere to one registered doctor on condition that the doctor is a "good doctor". The definition of a good doctor as provided by the participants was not based on strict clinical criteria but rather on recent experiences of care under a particular doctor. The typical good doctor was described as a popular, friendly person who does not discriminate, listens seriously to anything presented to him or her and examines you properly. He/she takes the patient's illness seriously, refers when necessary and gives sick leave that can be used to see a traditional healer (Chabikuli et al. 2008).

For Enablemed as $\mathrm{MHCO}$ it is important that clients are informed as to what their benefits are and how to access these benefits sensibly. The above investigations brought to the fore that it cannot be assumed that clients from different socio-cultural and economic backgrounds will spontaneously grasp the concept of managed health care and the rules and benefits of their medical aid package. For many of the clients, their packages, as administered by Enablemed, are their first medical fund they have ever participated in. Enablemed concluded from the results of these investigations that it would be worthwhile to revisit their existing communication system to find enhanced ways of communicating benefits to clients and to enable clients to utilise benefits correctly. The criteria for successful enablement are not only access to information or benefits, but a measurable indication that clients utilise these benefits appropriately. For example, it is not sufficient that clients know that they have to go to one registered doctor if it is evident from the administrator's call centre records that people do not adhere to this guideline and authorisation for medical treatment has to be declined.

The above studies disclosed that the MHCO's clients were not yet sufficiently knowledgeable regarding their benefits and that there was still much to be learnt about the perspective from their particular socio-economic and cultural backgrounds in order to predict their health care seeking behaviour. The preference to adhere or not with one registered doctor is but one example of how people's socio-cultural background and views influence their health care seeking behaviour. The type of relationship entry level clients have with their registered doctor as well as with the managed health care service provider influences the way in which they communicate with these parties. Focused on the question of interventions in the dynamics between managed health care role players, this clearly indicates that if one, then, aims at the responsible introduction of new means of personal communication between the three parties (patient and family, health care provider and medical insurance/medical aid), it would be misguided to assume that clients will automatically adopt new technologies according to the typical usage patterns thereof as prevalent in the milieu of the health care provider and agents of the medial insurance. The application of these technologies is embedded and takes place within an existing socio-cultural actuality. The question thus arises: could mobile phone technology be used to cost effectively facilitate managed health care benefits to 
clients, without incurring detrimental effects to other aspects of their quality of life? This question has to be answered in two phases: first an indication has to be given of the prevalence and usage patterns of mobile phones in low-income households and of the meaning of this phenomenon (\$4); second, given the limited information about user behaviour available, a heuristics has to be developed to form a framework in which user behaviour could be anticipated with sensitivity $(\$ 5)$.

\section{Socio-cultural significance of mobile phone availability in low-income households}

In December 2006 Murray and Tumbo conducted a baseline survey of the health status of 24 low-income communities surrounding the Lonmin Platinum mine in the Limpopo province. Apart from questions focussing on the health of respondents a section was also included to gather data regarding the communication means available to households. This information was important in order for Enablemed to determine if the utilisation of mobile phone technology as means to facilitate benefits to low-income managed health care clients was a realistic goal. A total of 560 households with 2666 household members were sampled.

The availability of means of communication as reported by primary caregivers in the households is summarised in the table below (Murray \& Tumbo 2007:125):

\begin{tabular}{||l||l||l||}
\hline \multicolumn{2}{|l|}{ Table 1: Available communication in households } \\
\hline \hline Communication available & Frequency & Percentage \\
\hline \hline Radio & 444 & 79.43 \\
\hline \hline TV & 337 & 60.29 \\
\hline \hline Telephone & 8 & 1.43 \\
\hline \hline Fax & 1 & 0.18 \\
\hline \hline Mobile phone & 409 & 73.17 \\
\hline \hline Personal computer & 5 & 0.89 \\
\hline \hline Internet access & 1 & 0.18 \\
\hline \hline E-mail & 3 & 0.54 \\
\hline \hline Mobile phone banking & 0 & 0.00 \\
\hline \hline
\end{tabular}

From the above table $(\mathrm{n}=559)$ it can be deducted that most households have radios (79.43\%), cell phones (73.17\%) and television sets (60.29\%) available as communication mediums. It is remarkable that only $1.43 \%$ of households have a telephone while $73.17 \%$ of households own a cell phone! This finding is even more thought provoking if one considers that, unlike the television and the radio, the mobile phone is the only to allow two-way communication. Only $0.89 \%$ of respondents have a personal computer while just $0.18 \%$ of respondents have internet access. None of the respondents reported that they have access to mobile phone banking. 
Respondents further reported that the majority of mobile phone users in their households are over 30 years of age and female. Of the caregivers who do own a mobile phone, only $12.64 \%$ had no education, while $26.43 \%$ had grade 11 to grade 12 schooling. Of the caregivers who do not own a mobile phone, $41.94 \%$ had no education, while $1.66 \%$ had grade 11 to grade 12 schooling or higher.

According to the respondents, $34.05 \%$ of mobile phone owners make a call at least once a day and $55.38 \%$ of mobile phone owners in all the communities receive an incoming call at least once a day. The number of people using the SMS function is a little bit smaller, with $36.84 \%$ of respondents never sending a SMS and $21.36 \%$ never receiving a SMS.

In most of the affluent parts of the world, the land-line telephone has become a standard piece of equipment over the last few decades. It belongs, with the fridge, the radio, the television and others, to the set of regular instruments that typically furnish the habitat of many households in many different cultural contexts. Within this context it plays an important role in the enhancement of dialogical and personalised communication. It serves to coordinate activities of individuals and families amongst one another and with the outside world. These phones also fulfil a function in maintaining and cultivating ties with people out of direct reach. Furthermore, phones could, especially in emergencies, take a key position to link the household with a broader system of support. Of these the link with medical service providers is of central importance for the current study.

The households in the above study could be considered part of the enormous wave of newcomers to telephonic services through the rapid spread of mobile phones in the developing world (for worldwide statistics, see ITU 2013). Two considerations prohibit one from considering these findings as ordinary. On the one hand the fact that an unparalleled spread of the use of mobile phones has arisen in an extremely short space of time without building on a historical precedent of the "normal" fixed household phone. On the other hand this new artefact, apart from being able to take exactly the same position as the former fixed telephone, is also characterised by an immense increase of its technical functionality. These two factors allow us to speak of a revolution concerning this element of the household existence, provided that we understand by a revolution a sudden dramatic change in historical continuity and nature of the system. The revolution in the spread of mobile telephony imposes the demand for an interpretation of the spread of mobile phones other than considering it a mere extension of the former telephone. Existing research on the quality-of-life impact of cell phones on their users has not sufficiently taken these conditions, and the uncertainty entailed in them, into consideration (cf. Sirgy et al 2007), beside the fact that it has been designed to validate user satisfaction after implementation.

\section{A Hermeneutic framework for the responsible introduction of mobile technology to low-income households}

\subsection{The Value of Hermeneutical Insight}

Now that we have commented on the roles and duties of the managed health care role players and explored the profile of the revolution in the spread of mobile telephony in our context of study, the next step is to ask what competency could be gained by the developers of a new communication system for the MHCO with regard to the unknown factors of humantechnology interaction in this project. We would like to argue that hermeneutical insight (i.e. insight gained from the general theory of understanding and interpretation) is valuable for 
the theoretical reflection on the conditions for the responsible application of mobile technology by such a MHCO for the following reasons:

- All hermeneutic theories are based on the temporality of human existence and their living contexts which imply that it is by its very nature suitable to handle phenomena of change.

- A general theory of hermeneutics maintains the inseparable link between technical change and changes on the levels of society and meaning.

- The project is about the establishment of a communication system, but communication has been generally argued by hermeneuticists to be much more than the mere transfer of bites of information from a sender to a receiver - it rather involves an array of factors from the living context of the partners in communication.

- In a context where the factor of cultural diversity is significant, but where the specifics thereof are largely unknown in the individual case, hermeneutics is capable of providing a general anthropological theory of interpretation that could render the structure according to which the appropriation of technical artefacts would take place. It doesn't predict the future, but holds the place of what might still come - and this in such a manner that all design and development that is based on it could accommodate changes.

- The hermeneutic approach to technology and technical change doesn't take its point of departure in a positive or negative evaluation of technics. In this regard it could in a sense be considered as a pre-normative interpretational activity concentrating on positive as well as of negative implications of technical change.

- Hermeneutics is suitable to provide an interpretational framework for the artefactual and the communicative aspect of the mobile phone at the same time.

- Hermeneutics is a practical philosophy - it takes the living human being (as individual and as member of society) and his/her understanding interaction with the world as the source of everything that is meaningful. Furthermore, since it centres in the capabilities of the human being - the "I can". As such it has proven to be easily compatible with the normative model of NOVA's Functional Households Programme, in which the functioning human being is central.

- For this reason, a hermeneutics of technical change is valuable since it is able to function in a heuristic manner in the preparatory reflection that precedes the normative evaluation of the possible effects of the application of mobile telephony on the quality of life of the households. As a framework by means of which the effects of the project's interventions could be anticipated, it plays a major role in sensitising the managed health care administrator to possible impact scenarios on the efficiency of the product that is being developed, as well as on the quality of life of the people involved.

\subsection{Overview of a general Hermeneutics of technical Change}

Guiding our interpretation of technical change is a broad understanding of basic anthropological developments: the human being, apart from being a biological entity, is historically constituted by at least three changing aspects and their changing interaction, namely the social aspect, the aspect of meaning and the technical aspect (this perspective is inspired by Leroi-Gourhan 1993). In undertaking to formulate a theory of the human experience of technical change (as has been done in more detail by Wolff 2012, and presented in outline here), one is obliged to take into account how the other constitutive aspects of the 
human being are changed at the same time and how they bear influence on the reception (or rejection) of new forms of technology.

The technical aspect of the human being could be considered to be constituted by three elements that constantly depend on one another: (i) the human being that participates in the technical system by means of a socially and individually acquired technical disposition (habitus), (ii) the systems of means (tools, forms of energy, procedures, institutions, etc.) and (iii) the interaction between the technical agent and the system in order to have some potential of the system and of the agent realised.

These three aspects of human technicity change over time because of easily identifiable interventions, for instance skill acquisition, the breakdown or modification of the system, ageing of the agent, etc. However, they continually constitute what could be called a technical figuration. The three-fold technical figuration undergoes change in very much the same way as the change in narrative figuration analysed by Ricoeur (see especially Ricoeur 1983:105169). According to him, the event of understanding a narrative presupposes a narrative disposition (or prefiguration), it needs a told or written narrative (that is the configuration) and, in the process of listening to or reading the narrative, one understands it while at the same time a world of self-interpretation of the reader/listener in response to the text is opened (which entails a refiguration of the initial prefiguration). In what follows, the textual and narrative hermeneutics of Ricoeur in its threefold structure will be adopted and adapted for the interaction between human beings and a changing technical environment. It should thus be clear that we adopt here a general anthropological perspective on the hermeneutic engagement of human beings and their technical environment (this perspective exceeds but encompasses the "hermeneutic technological relation" of agents to technical objects as presented by Ihde especially 1979:11-13 and 1990:80-97).

(i) Prefiguration - habitus

It is only on the basis of an implicit pre-understanding of action that one is capable of having any understanding at all of narrations on actions. In very much the same way as life is structured in an implicit narrative manner, it is also structured in an implicit technical manner. This implicit technicity of human existence - or the technical second nature - is the technical habitus. The habitus is the set of changing and interrelated capabilities that are sedimented in the human body (cf. Mauss [1934]1950 and Bourdieu 1980 in particular 8889). The process by which such capabilities become embodied and individualised starts in early childhood and continues (although at a decreasing rate) until death; it is the cumulative result of the individual's exposure to and appropriation of culturally specific forms of societal learning. Thus is shaped the bodily, pre-reflective mode of existence that Merleau-Ponty called "I can" (Merleau-Ponty 1945:160). More than a mere agglomeration of bodily knowhow's, the "I can" that is formed to a habitus is the way in which an individual is acquainted with the world. Very often this acquaintance does not constitute an arrangement of representations; in fact, it is rather a non-consciousness-centred, lived through familiarity with the world.

(ii) Configuration - autonomy of technical means

Technical means form an interrelated system that is characterised by autonomy in very much the same way as is the case with texts. The technical means are autonomous in the sense that they have an existence (1) independent from the intention of its inventor or fabricant, (2) always independent from the socio-cultural conditions in which it has been produced, at least 
in principle, and (3) independent from the intended user(s) (cf. Ricoeur 1986:207ff). In short, technical autonomy is the fact of the de-contextualisation of which technical means are capable (cf. Wolff 2006:34-37).

Of course, the de-contextualised technical means have the potential to be transferred and to be re-contextualised by a user in a new set of circumstances - just like a reader does with a text that is sent to him/her. But again, just like the text is at the mercy of the reader's capability to make sense of it, so the technical means is at the mercy of the technical agent who will interpret what that technical means is for and thus re-contextualise it. The autonomy or de-contextualisation of a technical means is suspended when that means is (re)inserted into a context of a project, in other words when the technical means serves to do this or that (see point iii below).

The "what it is for" of the technical means transfers in the autonomous technical means the possibility of doing something. It is as if the means contains an invitation to whoever will use it, to use it in a certain way or for a certain purpose. On the one hand, this remains only an invitation or a proposition of how to take benefit of the technical means; as stated, the event of re-contextualisation is at the mercy of the user of the technical means. The new user can use the technical means in a way that is worse or better for the purposes intended by the producer, or for different purposes altogether. On the other hand, it would be an error to think that the user has all the say in the practical meaning of the technical means. On the contrary, the very technical qualities of the means facilitate some actions and at the same time makes others more difficult. The event of suspending the autonomy of the technical means will thus be a confrontation of whatever the designer of the means invested in the means, but also the agility, inventiveness and cultural formation of the technical agent.

Though it is easy to follow the analysis above by imagining different kinds of tools and instruments, one should not forget that it actually describes the entire technical system that enjoys such a form of autonomy with which a particular socially situated individual could engage. This remark is of no slight importance, since it has been pointed out that the very use of technical means will be a confrontation between the technical means and the agent. What is at stake is the quality of this confrontation and thus, by extension, the kind of contribution that a set of technical means make to the quality of life of a particular person. Thus we need to go into further detail with this matter.

\section{(iii) Refiguration - confrontation of the agent with the technical means}

In the same way that the autonomy of technical means could be compared to the autonomy of a text, one could compare the engagement of the technical agent with the technical means as a kind of reading. Technical "reading" is the event of interplay between the prefigured technical habitus of the agent and the configured technical system. When the "I can" of the agent interacts with the facilitating technical qualities of the means, this gives rise to a (re)actualisation of the means, with the purpose of doing something. Something is used as something, for a purpose - thus could be summarised the lesson already learned from Heidegger (see Heidegger [1927]1993, chapters 3\&5 and in particular §32), namely that technical action is an understanding mode of existence. When using something as this or that, a world of possibilities is opened. We call it the world of the technical means. However, it is at the very same instant a world of possibilities of the technical agent. Thus, in very practical terms, the agent interprets himself/herself as agent in the use of the means. Furthermore, not only does the technical agent discover his/her own capabilities, but the technical second nature or habitus is changed in the process. 
When considering the confrontation of the agent with the technical means, all three aspects of human technicity (habitus, technical system and understanding interaction) thus enter into consideration. Furthermore, the aspects of human-hood, thus far left out of consideration (the social and the meaningful), necessarily impose themselves on the analysis.

This becomes apparent when it is considered that one doesn't read alone (cf. Ricoeur 1970:7). Reading is never solitary, since it is an acquired skill, not only of deciphering signs, but also of placing them within a horizon of socially construed meaning. The same holds for technical know-how: nobody exploits the technical possibilities of objects alone since one's very body holds in stock (amongst others) a socially or culturally acquired set of capabilities and the very end to which an object is used is stamped by socially informed meaning. Note that the idea of social determinism is rejected, but with it also the notion of the absolutely free, self-sufficient, individual subject.

The use of technical means situates that means within a context of use or a project. But this very project is an excellent vantage point from which to see that the technical understanding of technical events remain only a partial perspective; when human technicity is considered purely technically, it is not fully understood. One could, in fact, distinguish three different references or understandings of technicity:

- the technical reference, i.e. the internal reference of the constituting parts or elements of a technical mean to one another by means of their technical qualities

- the usage reference, i.e. the reference opened by the usage of a means within the context of a project, in other words the practical interpretation of something as a this or that, for this or that

- the symbolic reference, i.e. the reference beyond the technical qualities or usage to socio-cultural values or ideas, such as fashion, quality, luxury, etc. and that depends on the manner in which the (personal, cultural, technical) history and context of technical events informs the use of technical means.

\subsection{Contours for the interpretation of mobile telephony}

Within this framework of the hermeneutics of changing technical interaction, the mobile phone should be explored as a particular example. As a revolutionary new aspect of the household it should against this background be considered from a three-fold perspective that will take into account its technical axis, socially informed usage axis and symbolic-historical axis. These three axes that are in many regards intertwined correspond with the three-fold reference of all technicity, and with the three aspects of humans: technicity, sociality and meaning. These axes are the temporal trajectory that the changes of the three named sets of references undergo, both with regard to their constituting elements and their usage. Practically this means that the MHCO should consider all three of these aspects before implementing mobile applications to facilitate benefits to households:

i. Technical axis: The use of the mobile phone is made possible by 'upstream' requirements and opens towards 'downstream' implications or possibilities. Between the upstream and downstream is the mobile phone as artefact. Together these elements constitute the technical system of mobile telephony and constitute the first axis of its interpretation - the technical axis. This axis has to be analysed (1) from the perspective of the mobile phone itself (its internal functionalities and the way in which these functionalities operate in relation to the external usage network) and (2) as it fits into a broader technical, social and symbolic world of the user. All kinds of 
questions concerning the requirements for and capabilities to use mobile phones enter into play. To name only two relevant examples applicable for Enblemed's consideration: some clients may have sub-standard or aged mobile phones which places limitations on the type of messages that can be sent to these members and in some areas households might not have a reliable signal or network connection.

ii. Usage axis: The technical artefact takes on a meaning within a usage network or practical context. This means that the entire technical axis is subjected to what a particular individual does in each step of its technical possibilities, within a particular historical situation - this is the usage axis of the interpretation of technics. (In our case this concerns individuals from low-income sectors of society that will use their mobile phones for medical services provided by Enablemed.) It is a mobile phone only in as far as it is used, i.e. embedded within a context of actions, within a project. It is the concern, the "in order to..." that determines what the mobile phone is. The impact of the mobile phone to access benefits and as such contribute to improved quality of life can be established only if the usage (and not only the artefact) of the mobile phone is taken into account. In other words, this perspective on the usage of mobile phones enables the researcher to advance from the mere technical possibilities of mobile telephony to the question of the manner in which particular users are enabled or disabled to act or live in certain ways by the use they make of the aspect of the mobile phone system at their disposal. The entire range of socially acquired tendencies of action or action adopted under social pressure also enters into consideration here. Practically for Enablemed it implies that it is significant to understand if and how an illiterate mother reacts to an SMS reminder to take chronic medication. Not only the cost and technical axis as described above will contribute to the decision the MHCO makes to send either an SMS or a voice clip, but also the capabilities of this mother and her family such as their language ability and literacy level.

iii. Symbolic-historical axis: The entire complex of human technicity (habitus, technical system and technical usage) changes over time. This means that not only do the technical axis and usage axis of mobile telephony change, but it changes within a broader context of the changes of the entire technical system, that is in turn integrated into the larger complex of the symbolic and the social figurations that constitute human existence. From a particular position within this context, every particular agent, as member of a social figuration, derives (implicit or explicit) meaning of particular interactions with particular technical artefacts, in this case the mobile phone - this constitutes the symbolic-historical axis for the interpretation of the mobile phone. This axis opens up a perspective to the historically and culturally contingent horizon within which the usage of the technical qualities of the mobile phone will be a meaningful event in the life of the user. In order to analyse this axis, careful attention has to be given to the manner in which the artefact and its usage becomes incorporated in the sphere of symbols - in our case, the usage of mobile phones in the context of medical service provision, with all the ideas concerning gender, social status, intimacy, privacy, shame, social prejudice and the like that may be attached to it. Practically this could mean that it would be in some instances better for the MHCO to make a personal call to a client rather than sending a SMS, for example when a chronic patient is informed of his or her condition for the first time.

The complexity of the mobile phone as technical artefact is, however, considerably augmented by the fact that it is a means of communication. Not only is it subject to be 
interpreted as technical artefact, but most often it will serve to transmit messages. These may be textual, auditive, image or cinematographic. In all of these variants of transmissions, the user may be sender or receiver of messages. These two facts require a sharp vigilance from the researcher concerning the interplay of different layers of signification and agency - the active user of the mobile phone may, for instance, be passively subjected to a message which he/she actively inserts into a meaningful context.

\section{Conclusion: Recommendations for future application}

The above hermeneutics of technical change and its application on the mobile phone provides the broad framework for understanding and situating present and future changes that may impact on the nature and evaluation of the use of mobile phones by the MHCO's clients, as in the case of Enablemeds relation with low-income, entry-level clients. The framework is designed to make a contribution to the preparation (1) for the development of a practical and effective communication system, but also (2) for the evaluation of the technical changes involved in this project with regard to its users' quality of life.

On the practical side, this framework points out factors that would constitute and influence the proposed mobile phone usage; it presented a theory of the process by which newly transferred technologies are interpretatively accommodated into the life-world of new users. In turn, the number of known, or probable hypothetical, permutations of the prefiguration of the clients (for instance the phenomenon of doctor hopping or the problem of illiteracy) should be confronted with the proposed changes in the figuration (communication system that may for instance require stability with regard to the choice of doctor and propose the usage of SMS's) in order to establish if it could likely be expected to have the required results (good communication as determined by the task giver, Enablemed in the example we used here). In the process questions should be asked concerning the possible need for supplementary interventions (for instance training of users) in order to form a habitus that would enable the users (both employees of the $\mathrm{MHCO}$ and its clients) to take full advantage of the communication system, to see what practical obstacles (technical, social or symbolic) may arise during usage, and to adapt the project accordingly. If, during the later phases of implementation, deficiencies occur in the product or its usage, the hermeneutic framework could then be deployed as a guide for troubleshooting. Furthermore, the framework forms the basis of any research tool that will be developed to evaluate the effectiveness of the product.

On the normative side, this hermeneutic approach provides a guide for the first brainstorming that is necessary to pre-empt possible detrimental effects of the technical innovation and intervention that the project entails on the quality of life of the end-users. It should be noted that this implies a prior commitment to responsible innovation, which entails understanding the technical and social implications of a particular innovation, but also making a conscious decision that the best available measurement tools will be employed to measure the impact of a newly designed product or service on the clients that employ these means. Furthermore, the analysis of the embeddedness of the technical means within its setting of society and meaning helps to cultivate a vigilance for possible practical difficulties (like culturally distinct perspectives on health treatment) and possible ethical mistakes (like the one-sided imposition of new usage patterns by a MHCO). In short, the hermeneutic analysis brings a competence in the inbuilt uncertainties of the project that allows the MHCO (or any organisation faced with similar circumstances) to act in a more responsible manner when introducing mobile (or other technological) applications for the facilitation of managed health care benefits. 
Employment of this hermeneutic framework would imply sensitivity for the fact that, in a context that has witnessed a sudden and dramatic rise in the use of mobile phones, it cannot be assumed that people have formed a habitus of acquaintance with this apparatus in the same way as in contexts or societies where people have been using telephones for decades (without any value judgement implied) and where, furthermore, their usage of telephony is embedded in an entirely different socio-technical environment.

The audio and visual functions of the mobile phone create new possibilities for the MHCO to communicate, for instance, with illiterate people. It could also facilitate new opportunities for communication with people that are otherwise badly integrated into the existing technical system of communication, such as the Limpopo communities in the case study under consideration. These possibilities could best be utilized if the existing prefiguration of people in these communities (as sociological generalisation) is recognized and the particular patterns of usage and symbolic-historical horizon in which they give meaning to it are taken into account. The criteria for the successful implementation of new communication technologies should therefore not be measured exclusively in terms of the availability of products and services, but at least also in terms of the number of clients that actively employ these technologies to capitalise on their benefits. On the side of the $\mathrm{MHCO}$, this would require openness to the diversity of their clients and recognition of differences. Whereas the implementation of new technologies for communication will require adaptation from the part of the clients, the $\mathrm{MHCO}$ could reciprocate by e.g. adopting a code of conduct that would allow for negotiation concerning these patterns of communication with the clients.

Failure to take these considerations seriously would mean running the risk of managed health care forming a dominating interpretational force that accompanies the recontextualisation of the autonomous technical artefact. This could happen if the product is enforced or available to people by means of packaged services that imply predetermined usage patterns that were modelled on social and symbolic presuppositions that do not fit theirs or that enforce existing social injustices (Selinger's study on the social effects of the Grameen Bank's "Village Phone project" in Bangladesh [Selinger 2008] illustrates this point). Similarly, failure in the responsible introduction of new usage of technology could take place if the necessary social accompaniment for the refiguration of the people's prefiguration is not realised in such a way that it serves to re-contextualise this technical means to actualise the benefits intended.

Responsible introduction of mobile technology by a MHCO such as Enablemed - this has been our argument - consists of combining (1) available information regarding mobile phone availability and usage patterns amongst clients and (2) the development of technologies of interaction between service provider and client, (3) with a heuristics provided by a hermeneutics of technical change. This type of approach is of particular importance for a MHCO to support its commitment to the improvement of the quality of life of the clients from low-income contexts with multiple factors of uncertainty. The introduction of mobile phones to low income households will have the best chance of being "enabling" if the MHCO takes responsibility to avoid the ethical pitfalls of a one-sided technocratic implementation of this technology. Our notion is that the hermeneutic framework as presented can be of help to managed care administrators in this regard.

\section{References}

Bourdieu, P. 1980. Le sens pratique. n.p.: Minuit. 
Chabikuli, N., Murray, M., Fehrsen, S.G. and Hugo, J.F. 2008. Choosing, changing or adhering to a registered doctor in a managed care plan: what will it take? A qualitative survey in rural Mpumalanga, South Africa. South African Family Practice, 50 (4), 66$66 \mathrm{~d}$.

Heidegger, M. [1927]1993. Sein und Zeit. Tübingen: Max Niemeyer Verlag.

Ihde, D. 1979. Technics and Praxis. Dortrecht, Boston, London: D. Reidel Publishing Company.

Ihde, D. 1990. Technology and the lifeworld. From garden to earth. Bloomington/ Indianapolis: Indiana University Press.

International Telecommunication Union (ITU). 2013, http://www.itu.int/en/ITUD/Statistics/Pages/default.aspx.

Jonas, H, 1979. Das Prinzip Verantwortung. Versuch einer Ethik für die technologische Zivilisation. Frankfurt-am-Main: Suhrkamp.

Leroi-Gourhan, A. 1993. Gesture and Speech. Cambridge Massachusetts \& London: MIT Press.

Mauss, M [1934]1950. Les techniques du corps. In: Sociologie et anthropologie, Paris: P.U.F, 365-386.

Merleau-Ponty, M. 1945. Phénoménologie de la perception. Paris: Gallimard.

Murray, M. 2005. Makoti Health Plan as Managed by Enablemed. Member Contentment Investigation. Research Report to Enablemed Management: Unpublished.

Murray, M. and Tumbo, J. 2007. Health Status of Communities around Lonmin Platinum Limpopo: A Baseline Survey. Research Report to Lonmin Management: Unpublished.

National Centre for Biotechnology Information (NCBI), Electronic database including the U.S. National Library of Medicine, accessed on 24 January 2009 at http://www.ncbi.nlm.nih.gov/sites/entrez (search terms: "managed care")

Ricoeur, P. 1970. Le conflit des interprétations. Essais d'herméneutique I. Paris: Editions du Seuil.

Ricoeur, P. 1983. Temps et Récit, 1. L'intrigue et le récit historique. Paris: Editions du Seuil.

Ricoeur, P. 1986. Du texte à l'action. Essais d'herméneutique II. Paris: Editions du Seuil.

Selinger, E. 2008. Does microcredit “empower"? Reflections on the Grameen Bank debate. Human Studies, 31, 27-41.

Sirgy, J.M., Lee, D., Kamra, K. \& Tidwell, J. 2007. Developing and Validating a Measure of Consumer Well-Being in Relation to Cell Phone Use. Applied Research in Quality of Life, 2, 95-123.

Wolff, E. 2006. Transmettre et interpréter: le temps du dialogue. Médium 6, 30-47.

Wolff, E. 2012. "Habitus - means - worldliness. Technics and the formation of "civilisations". In: Kozlarek, O., Rüsen, J. \& Wolff, E. eds. Shaping a Humane World - Civilizations, Axial Times, Modernities, Humanisms, Bielefeld: Transcript, 25-53. 